\title{
A influência das atividades acadêmicas complementares na atuação profissional dos egressos de enfermagem
}

\author{
The influence of complementary academic activities on the professional performance of \\ nursing graduates
}

\section{Influencia de las actividades académicas complementarias en el desempeño profesional de los egresados de enfermería}

\author{
Alessandra Aparecida de Saldes ${ }^{1}$, Luciana Marques Andreto ${ }^{1}$, Tatiana Cristina Montenegro \\ Ferreira $^{1 *}$, Verônica Kelly do Nascimento Ramos ${ }^{1}$.
}

\begin{abstract}
RESUMO
Objetivo: Analisar a influência das atividades acadêmicas complementares na atuação profissional dos egressos do curso de enfermagem de uma Instituição de Ensino Superior do estado de Pernambuco. Métodos: Estudo do tipo descritivo, retrospectivo e de análise quantitativa, realizado em uma faculdade de enfermagem na cidade de Recife. A amostra foi composta por 85 egressos. Os dados foram coletados através de um questionário eletrônico semiestruturado e a análise dos dados foi feita através do Software Excel, a partir de estatística descritiva simples. O trabalho foi aprovado pelo Comitê de Ética e Pesquisa, parecer no 4.329.374. Resultados: A pesquisa conseguiu demonstrar o perfil socioeconômico, demográfico, acadêmico e profissional dos egressos, além de evidenciar que as atividades acadêmicas complementares contribuíram para a atuação profissional dos enfermeiros no mercado de trabalho. Foi demonstrado que o estágio extracurricular foi o mais citado como atividade que contribui como ferramenta para galgar uma alocação profissional como também uma estratégia para gerar relacionamentos interpessoais e profissionais com foco no crescimento e desenvolvimento da profissão. Conclusão: Conclui-se que as atividades complementares exercidas durante a graduação, contribuem positivamente na atuação profissional dos egressos do curso de enfermagem, principalmente os estágios e monitorias.
\end{abstract}

Palavras-chave: Enfermagem, Educação em enfermagem, Mercado de trabalho.

\begin{abstract}
Objective: To analyze the influence of complementary academic activities on the professional performance of graduates of the nursing course at a Higher Education Institution in the state of Pernambuco. Methods: Descriptive, retrospective and quantitative analysis study, carried out at a nursing college in the city of Recife. The sample consisted of 85 graduates. Data were collected using a semi-structured electronic questionnaire and data analysis was performed using Excel software, using simple descriptive statistics. The study was approved by the Ethics and Research Committee, opinion No. 4,329,374. Results: The research was able to demonstrate the socioeconomic, demographic, academic and professional profile of the graduates, in addition to showing that the complementary academic activities contributed to the professional performance of nurses in the labor market. It was demonstrated that the extracurricular internship was the most cited as an activity that contributes as a tool to achieve a professional allocation as well as a strategy to generate interpersonal and professional relationships with a focus on the growth and development of the profession. Conclusion: It is concluded that the complementary activities performed during the graduation, positively contribute in the professional performance of the graduates of the nursing course, mainly the internships and monitoring.
\end{abstract}

Keywords: Nursing, Nursing education, Labor market.

\section{RESUMEN}

Objetivo: Analizar la influencia de las actividades académicas complementarias en el desempeño profesional de los egresados de la carrera de enfermería en una Institución de Educación Superior del estado de Pernambuco. Métodos: estudio de análisis descriptivo, retrospectivo y cuantitativo, realizado en una facultad de enfermería de la ciudad de Recife. La muestra de estudio fue censal, con 85 egresados al final. Los datos se recolectaron a través de un cuestionario electrónico semiestructurado y el análisis de los datos se realizó mediante el software Excel, utilizando estadística descriptiva simple. El estudio fue aprobado por el Comité de Ética e Investigación, dictamen No. 4.329.374. Resultados: La investigación logró demostrar el perfil socioeconómico, demográfico, académico y profesional de los egresados, además de mostrar que las actividades académicas complementarias contribuyeron al desempeño profesional de las enfermeras en el mercado laboral. Se demostró que la pasantía extraescolar fue la más citada como una actividad que aporta como herramienta para lograr una asignación profesional así como una estrategia para generar relaciones interpersonales y profesionales con foco en el crecimiento y desarrollo de la profesión. Conclusión: Se concluye que las actividades complementarias realizadas durante la graduación, contribuyen positivamente en el desempeño profesional de los egresados de la carrera de enfermería, principalmente las pasantías y el seguimiento.

Palabras clave: Enfermería, Educación en enfermería, Mercado laboral. INTRODUÇÃO

${ }^{1}$ Faculdade Pernambucana de Saúde, Recife - PE. *E-mail: tatiana.montenegro@fps.edu.br 
A formação do enfermeiro no Brasil sofreu transformações ao longo da sua trajetória, devido às exigências do mercado de trabalho, às mudanças no Sistema de Saúde e as novas descobertas tecnológicas e científicas cada vez mais complexas. Em meio às crescentes transições e exigências, observa-se que a vinculação da teoria com a prática ainda não acontece como deveria, muitas vezes explorada superficialmente ao longo da trajetória acadêmica do enfermeiro. Tal afirmativa pode ser comprovada quando o recém-formado se depara com situações no ambiente profissional que não foram vivenciadas durante sua graduação ou foi abordado de modo distinto da realidade profissional, implicando na qualidade de sua assistência (BARBOSA ACS, et al., 2019).

Diante disso, o processo formativo e o perfil do enfermeiro para inserção do mercado de trabalho são pautas relevantes que merecem espaço para discussão. Essa formação é entendida como um processo que visa conhecimentos, competências, habilidades e atitudes exigidas para o exercício da enfermagem (PUSCHEL VAA, et al., 2017). As Diretrizes Curriculares Nacionais (DCN) para a Graduação em Enfermagem (Resolução CNE/CES № 3, de 7 de novembro de 2001), estabeleceu alguns objetivos que precisam ser analisados no ensino superior:

“(...) eles são focados nas competências e habilidades, ressaltando os aspectos de: atenção à saúde; tomada de decisões; comunicação; liderança; administração e gerenciamento e educação permanente" (BRASIL, 2001).

Com base nessas DCN, o perfil do profissional enfermeiro deve ser generalista, humanista, crítico e reflexivo, capacitado a atuar profissionalmente pautado em princípios éticos (BRASIL, 2001).

Generalistas são profissionais preparados cientificamente, humanisticamente e com capacitação suficiente para avaliar, identificar e implementar as necessidades de saúde e cuidados de pessoas saudáveis ou doentes, das famílias e comunidade considerando o perfil epidemiológico da população e preocupados com a implementação de ações que atendam às necessidades do ser humano em toda sua complexidade. (MASSAROLI A, 2019).

A formação humanista é aquela que entende o indivíduo como um todo, que usa o olhar holístico, tratando o outro com suas particularidades. É preciso ser empático e autêntico. Com este olhar, é necessário fazer uma transformação da educação e da enfermagem, transformando-a em uma profissão com assistência humanizada (BECERRIL LC, 2016).

Com a formação crítica do estudante, ele encontrará facilmente soluções para os problemas presentes no cotidiano de sua área de atuação, visto que esta forma de pensar constitui-se em um componente essencial para a tomada de decisão. Além disso, torna possível compreender as contradições presentes na rotina, assim como refletir sobre as possíveis intervenções a serem realizadas, caracterizando-se em uma maneira de atuação em que envolve conhecimentos, experiências, disposições e habilidades intelectuais (SOUZA JDFS, 2017). O processo de formação reflexivo permite que o indivíduo reproduza conhecimentos com base em suas vivências práticas. Portanto, observa-se que é através da reflexão, que se acha uma solução para os problemas enfrentados no cotidiano (NETTO L, et al., 2018).

As atividades complementares constituem carga horária obrigatória pra conclusão do curso, conforme DCN do curso de enfermagem. Essas atividades possibilitam ao aluno aliar o conhecimento teórico com a prática, além de incentivar a pesquisa, a extensão e o ensino. Se apresentam em modalidades diversificadas como monitorias, iniciação científica, projeto de extensão, workshops, congressos, cursos livres, estágios não obrigatórios, entre outros. Caracterizam relevância para enriquecer o currículo, além de aprimorar e acrescentar novas experiências para a vida do estudante. Dessa maneira, faz com que o estudante tenha autonomia, desenvolvendo um profissional proativo e que busca explorar novas ideias. Portanto, é importante que os acadêmicos reconheçam essas atividades não apenas com o intuito de completar a carga horária do curso, mas sabendo que essas atividades irão contribuir para a sua inserção no mercado de trabalho (CRUZ MLS, et al., 2020).

A inserção profissional, é motivo de preocupação para muitos estudantes, pois o mercado de trabalho se tornou mais competitivo. Por isso, é necessário que os enfermeiros se capacitem, durante e após a graduação, participando de cursos de aprimoramentos, aperfeiçoamentos, pós-graduações, buscando sempre 0 
conhecimento para estarem aptos e habilitados a exercer a profissão. O mercado de trabalho necessita de profissionais que atuem no enfrentamento dos graves problemas de saúde da nossa sociedade com humanização e eficácia (RODRIGUES CDS, 2020).

No mercado de trabalho é comum se destacar aqueles que tiveram um melhor desenvolvimento durante a graduação, ou seja, uma formação pautada em habilidades e competências com foco na capacidade de propor estratégias para o saber agir diante de situações que possam surgir e procurar soluções para esses problemas. A articulação da teoria com a prática faz uma aproximação do mundo do ensino com o mundo do trabalho. A associação da pesquisa com o ensino, a construção curricular, participação de atividades complementares e o processo de acompanhamento até o término do curso, fortalece o processo de formação (RODRIGUES CDS, 2020).

O acompanhamento de egressos possibilita a compreensão de contribuições do processo de capacitação do enfermeiro, tendo em vista as mudanças e as exigências no mercado de trabalho, o reconhecimento profissional, entre outros fatores (SOUZA NVDO, 2017). Dessa forma, o estudo teve como objetivo analisar a influência das atividades acadêmicas complementares na atuação profissional dos egressos do curso de enfermagem de uma Instituição de Ensino Superior do estado de Pernambuco.

\section{MÉTODOS}

Trata-se de um estudo descritivo, retrospectivo, de abordagem quantitativa. A amostra foi tipo censitária, representada por 663 egressos do curso de enfermagem de uma Instituição de Ensino Superior (IES), localizada no Estado de Pernambuco, entre os anos de 2009 a 2020. Entretanto, responderam ao questionário, apenas 121 egressos, e, somente 85 foram elegíveis para a pesquisa, pois atenderam aos critérios de inclusão.

A coleta de dados foi realizada de forma remota, através de questionário eletrônico estruturado via Google Forms, enviado para o e-mail e WhatsApp dos possíveis participantes. Os dados foram coletados entre novembro e dezembro de 2020. Um lembrete foi reenviado a cada sete dias, via e-mail e WhatsApp para os egressos que tiveram os dados de contato validados e que não responderam ao instrumento de coleta dentro do período.

As informações de contato foram disponibilizadas pela coordenação do Programa de Acompanhamento dos Egressos (PAEG) da IES. Foram excluídos os egressos envolvidos na pesquisa, os que estavam com os dados de contatos desatualizados, os que não responderam ao questionário, além dos que não exercem a enfermagem.

O instrumento utilizado continha 26 questões, sendo 24 objetivas e duas abertas, divido em seções, a saber: dados sociodemográficos, dados profissionais, desenvolvimento profissional e dados acadêmicos. Os dados coletados foram agrupados em planilhas e tratados no programa Excel, executado análises descritivas, exibindo valores absolutos e percentuais das variáveis.

Este trabalho foi submetido ao Comitê de Ética e Pesquisa (CEP) da Faculdade Pernambucana de Saúde (FPS), conforme Resolução no 510/16 e aprovado pelo parecer CAAE № 4.329 .374 de 08 de outubro de 2020. O mesmo seguiu todas as recomendações para pesquisas envolvendo seres humanos e todos os participantes receberam e assinaram o Termo de Consentimento Livre e Esclarecido.

\section{RESULTADOS}

Dos 663 enfermeiros formados pela IES, 121(18,25\%) responderam o formulário, dos quais $36(5,42 \%)$ não exercem a profissão de enfermeiro, $312(47,06 \%)$ não foram localizados, um $(0,15 \%)$ não aceitou participar, um (0,15\%) estava envolvido na pesquisa e 228 (34,39\%) não responderam ao formulário. Ao final, a amostra foi composta por 85 egressos. Em relação aos dados sociodemográficos, observa-se que a amostra foi composta em sua maioria por mulheres $(91,8 \%)$, autodeclaradas brancas $(56,5 \%)$, com idade entre 22 e 30 anos $(60 \%)$, casados $(55,3 \%)$ e residentes na capital $(50,6 \%)$ (Tabela 1). 
Tabela 1 - Caracterização sociodemográfica dos egressos de enfermagem de uma IES de Pernambuco, $\mathrm{n}=85$.

2021.

\begin{tabular}{|c|c|c|}
\hline Variáveis & $\mathrm{N}=85$ & $\%$ \\
\hline \multicolumn{3}{|l|}{ Sexo } \\
\hline Feminino & 78 & 91,8 \\
\hline Masculino & 7 & 8,2 \\
\hline \multicolumn{3}{|l|}{ Idade } \\
\hline 22 a 30 anos & 51 & 60 \\
\hline 30 a 40 anos & 27 & 31,8 \\
\hline$>40$ anos & 7 & 8,2 \\
\hline \multicolumn{3}{|l|}{ Cor/Raça } \\
\hline Branca & 48 & 56,5 \\
\hline Preta & 11 & 12,9 \\
\hline Amarela & 9 & 10,6 \\
\hline Outros & 19 & 20 \\
\hline \multicolumn{3}{|l|}{ Estado civil } \\
\hline Casado (a) & 47 & 55,3 \\
\hline Solteiro (a) & 33 & 38,8 \\
\hline Outros & 5 & 3,5 \\
\hline \multicolumn{3}{|l|}{ Município de residência } \\
\hline Recife & 43 & 50,6 \\
\hline Jaboatão dos Guararapes & 12 & 15,2 \\
\hline Olinda & 4 & 4,7 \\
\hline Outros & 25 & 29,5 \\
\hline
\end{tabular}

Fonte: Saldes AA, et al., 2021.

Quanto ao perfil de formação dos egressos, nota-se que a maioria se concluiu o curso entre 2015 e 2020 $(57,6 \%)$ e custeou por meio de recursos próprios (32,9\%). Além disso, quando questionados sobre as atividades complementares exercidas durante a graduação, verificou-se que mais da metade não participou de projetos de extensão $(68,2 \%)$, de igual modo para monitoria $(67,0 \%)$, para projetos de iniciação científica $(69,4 \%)$ e para estágios extracurriculares (44,7\%) (Tabela 2$)$.

Tabela 2 - Perfil acadêmico dos egressos de enfermagem de uma IES de Pernambuco, n=85. 2021.

\begin{tabular}{|c|c|c|}
\hline Variáveis & $\mathrm{N}=85$ & $\%$ \\
\hline \multicolumn{3}{|l|}{ Ano de Conclusão } \\
\hline 2009.2 a 2014.2 & 36 & 42,3 \\
\hline 2015.1 a 2020.1 & 49 & 57,6 \\
\hline \multicolumn{3}{|l|}{ Recursos para custeio do curso } \\
\hline Próprios & 28 & 32,9 \\
\hline Família & 22 & 25,9 \\
\hline PROUNI & 13 & 15,3 \\
\hline FIES & 18 & 21,2 \\
\hline Outros & 03 & 4,7 \\
\hline \multicolumn{3}{|l|}{ Participação em Projetos de Extensão } \\
\hline Participou em 1 projeto & 16 & 18,8 \\
\hline Participou em mais de 1 projeto & 11 & 12,9 \\
\hline Não participou & 58 & 68,2 \\
\hline \multicolumn{3}{|c|}{ Participação em Programa de Monitoria } \\
\hline Foi monitor durante 1 semestre & 14 & 16,5 \\
\hline Foi monitor em mais de 1 semestre & 14 & 16,5 \\
\hline Não participou & 57 & 67,0 \\
\hline \multicolumn{3}{|c|}{ Participação em Projetos de Iniciação Científica } \\
\hline $\mathrm{PIBIC}$ & 14 & 16,5 \\
\hline PIC & 08 & 9,4 \\
\hline $\mathrm{PIBIC} / \mathrm{PIC}$ & 04 & 4,7 \\
\hline Não participou & 59 & 69,4 \\
\hline \multicolumn{3}{|c|}{ Participação em Estágio extracurricular } \\
\hline Por menos de 1 semestre & 05 & 5,9 \\
\hline Por 1 semestre & 10 & 11,8 \\
\hline Por 2 semestres & 16 & 16,8 \\
\hline Por mais de 2 semestres & 16 & 16,8 \\
\hline Não participou & 38 & 44,7 \\
\hline
\end{tabular}

Fonte: Saldes AA, et al., 2021. 
A respeito do perfil profissional dos participantes, foi observado que a maioria conseguiu o primeiro emprego com um a três meses de formação (49,4\%), atualmente possuem um vínculo empregatício $(69,4 \%)$, com jornada de trabalho de 40 horas semanais sendo a mais prevalente $(45,9 \%)$. Trabalham no turno diurno $50,6 \%$ dos participantes, em instituição pública (40\%) e 37,6\% ganham até três salários mínimos (Tabela 3).

Tabela 3 - Caracterização do perfil profissional dos egressos de enfermagem de uma IES de Pernambuco, $\mathrm{n}=85.2021$.

\begin{tabular}{|c|c|c|}
\hline Variáveis & $\mathrm{N}=85$ & $\%$ \\
\hline \multicolumn{3}{|l|}{ Alocação no primeiro emprego } \\
\hline De 1 a 3 meses & 42 & 49,4 \\
\hline De 3 a 6 meses & 13 & 15,3 \\
\hline De 6 meses a 1 ano & 14 & 16,5 \\
\hline Mais de 1 ano & 16 & 18,8 \\
\hline \multicolumn{3}{|l|}{ Vínculos empregatícios } \\
\hline 1 vínculo & 59 & 69,4 \\
\hline 2 vínculos & 23 & 27,1 \\
\hline Mais de 2 vínculos & 03 & 3,5 \\
\hline \multicolumn{3}{|l|}{ Jornada de trabalho semanal } \\
\hline Menos de 30h & 05 & 5,9 \\
\hline $30 \mathrm{~h}$ & 12 & 14,1 \\
\hline $40 \mathrm{~h}$ & 39 & 45,9 \\
\hline $44 \mathrm{~h}$ & 10 & 11.4 \\
\hline $60 \mathrm{~h}$ & 08 & 9,4 \\
\hline Mais que $60 \mathrm{~h}$ & 11 & 12,9 \\
\hline \multicolumn{3}{|l|}{ Turno de trabalho } \\
\hline Diurno & 43 & 50,6 \\
\hline Noturno & 12 & 14,1 \\
\hline Ambos os turnos & 30 & 35,3 \\
\hline \multicolumn{3}{|c|}{ Forma de ingresso no emprego atual } \\
\hline Seleção por concurso & 07 & 8,2 \\
\hline Através de testes e entrevistas & 39 & 45,9 \\
\hline Convite do empregador & 14 & 16,5 \\
\hline Outros & 25 & 29,4 \\
\hline \multicolumn{3}{|c|}{ Natureza jurídica da Instituição em que trabalha } \\
\hline Pública & 34 & 40 \\
\hline Privada & 16 & 18,8 \\
\hline Pública/Privada & 07 & 8,2 \\
\hline Filantrópica & 12 & 14,1 \\
\hline Outras & 16 & 18,8 \\
\hline \multicolumn{3}{|l|}{ Média Salarial mensal } \\
\hline Até 2 salários mínimos & 21 & 24,7 \\
\hline Até 3 salários mínimos & 32 & 37,6 \\
\hline Até 4 salários mínimos & 11 & 12,9 \\
\hline Acima de 4 salários mínimos & 21 & 24,7 \\
\hline
\end{tabular}

Fonte: Saldes AA, et al., 2021.

Dos egressos que responderam ter cursado outra graduação, apenas dois $(2,3 \%)$ afirmaram ter sido área da saúde. Quanto a realização de especializações, 67,1\% afirmaram que sim, na modalidade Latu Senso, com área predominante em UTI e Urgência e emergência, 18,8\% e 14,1\%, respectivamente. Declararam ter participado de eventos científicos após a formação 43,5\%, em pelo menos duas vezes ao ano (Tabela 4). 
Tabela 4 - Desenvolvimento profissional de egressos de enfermagem de uma IES de Pernambuco, $\mathrm{n}=85$. 2021.

\begin{tabular}{lcc}
\hline Variáveis & $\mathrm{N}=85$ & $\%$ \\
\hline Fez outra graduação & 82 & 96,5 \\
\hline Não & 2 & 2,3 \\
Sim, em outra área da saúde & 1 & 1,2 \\
Sim, em uma área que não é da saúde & 16 & 18,8 \\
\hline Fez especialização & 57 & 67,1 \\
\hline Não & 08 & 9,4 \\
Sim, Latu senso mínimo de 360h & 03 & 3,5 \\
Sim, residência & 01 & 1,9 \\
Sim, mestrado & & 18,8 \\
Sim, doutorado & 16 & 18,8 \\
\hline Área de especialização & 16 & 14,1 \\
\hline Não tenho especialização & 12 & 11,8 \\
UTI & 10 & 9,4 \\
Urgência e emergência & 8 & 27,0 \\
Gestão & 23 & \\
Saúde da mulher & & 45,9 \\
Outros & 39 & 43,5 \\
\hline Participa de eventos científicos & 37 & 10,6 \\
\hline Não & 09 & \\
Sim, pelo menos 2 eventos por ano & & \\
Sim, mais de 2 eventos por ano & & \\
\hline
\end{tabular}

Fonte: Saldes AA, et al., 2021.

Observa-se que 94,1\% dos egressos afirmam que as atividades complementares durante a graduação contribuíram na sua atuação profissional. Dentre as atividades que mais contribuíram, foram destacadas os estágios extracurriculares (64,7\%) e as monitorias (15,3\%). Quando questionados como as atividades complementares contribuíram para a vida profissional, a maioria respondeu que foi por possibilitar a associação da teoria à prática (30\%) (Tabela 5).

Tabela 5 - Contribuição das atividades complementares para inserção no mercado de trabalho, na opinião dos egressos de enfermagem de uma IES de Pernambuco, n=85. 2021.

\begin{tabular}{lcc}
\hline Variáveis & $\mathbf{N}$ & $\%$ \\
\hline $\begin{array}{l}\text { As atividades acadêmicas complementares realizadas durante a } \\
\text { graduação contribuíram para a atuação profissional * }\end{array}$ & \\
\hline Sim & 80 & 94,1 \\
Não & 5 & 5,9 \\
\hline Qual atividade complementar foi determinante na carreira * & 55 & 64,7 \\
\hline Estágio Extracurricular & 13 & 15,3 \\
Monitoria & 6 & 7,0 \\
Projetos de Extensão & 11 & 12,9 \\
Projetos de Iniciação Científica & & \\
\hline Como as atividades complementares contribuíram & vida & 30 \\
profissional * & & 6,2 \\
\hline Associação da teoria com a prática & 5 & 15 \\
Desenvolvimento do olhar crítico & 12 & 48,7 \\
Contribuição na avaliação curricular de seleções & 39 & \\
Outras formas & & \\
\hline
\end{tabular}

Nota*: o N pode sofrer variações, pois algumas respostas foram abertas ou de múltipla escolha.

Fonte: Saldes AA, et al., 2021.

\section{DISCUSSÃO}

A enfermagem é uma profissão historicamente exercida por mulheres e o resultado encontrado neste estudo corrobora com essa afirmativa. O papel da mulher atrelada ao ser responsável pelo cuidado com a família e as tarefas domésticas fizeram com que ela se identificasse com profissões que remetessem a essas atribuições, como a enfermagem. Assim, a mulher se adaptou e com o passar do tempo e as transformações na sociedade, esse ofício se estabeleceu como uma ciência (BASTOS MF e SCARABELI ZN, 2020). Porém, a função de enfermeiro não está limitada a prestação do cuidado. Ela alcança a gestão da equipe de 
enfermagem, a gerência de serviços, permeia a educação em saúde a favor da promoção e prevenção de agravos, além da educação continuada. Todas atribuições alicerçadas numa construção através de conhecimento técnico-científico baseada em evidências que the garante autonomia no exercício de suas funções (LEAL LA, et al., 2018).

No que se refere à idade dos egressos, evidencia-se que há uma mudança no perfil etário dos enfermeiros. Pesquisa realizada pelo Conselho Federal de Enfermagem (COFEN) que traçou o perfil da enfermagem no Brasil, mostra que a profissão se apresenta mais jovem (COFEN, 2015). Este resultado pode ser explicado devido ao aumento de abertura de IES privadas e a oferta ampliada de vagas para este curso. Segundo resultados estatísticos do Instituto Nacional de Estudos e Pesquisas Educacionais Anísio Teixeira (INEP), o curso de enfermagem se mantém como quinto colocado numa lista dos dez maiores cursos de graduação em número de matrícula do país, com um crescimento de mais de 40\% entre os anos de 2009-2019 (BRASIL, 2019).

O estudo em tela exibe predominância de egressos que se autodeclaram de cor de pele branca. Resultados semelhantes que foram encontrados em estudos publicados acerca do perfil sociodemográfico dos enfermeiros em diferentes regiões do Brasil, afirma que apesar dos pretos e pardos representarem a maioria dos trabalhadores no país, na enfermagem essa realidade ainda está em construção (SILVA KL, et al., 2016; MACHADO MH, et al., 2016). Essa relação pode ser explicada devido às desigualdades sociais baseadas na raça/cor, visto que historicamente as pessoas de pele preta ou parda são segregadas na sociedade. Políticas Públicas com foco na garantia de acesso dessa população a educação superior, como as cotas, ainda apresenta um resultado aquém do esperado para essa iniciativa (BARBOSA ACS, et al., 2019).

Percebe-se que a maior parte dos egressos residia na região metropolitana. Achado semelhante em outra pesquisa, evidenciou a migração de jovens dos municípios do interior do Estado, em busca de melhores oportunidades de acesso à educação e ao emprego, fomentado pelas escolhas das IES em estabelecer seus campus nas capitais e em municípios circunvizinhos, devido a estratégias de negócio, a fim de gerar maiores oportunidades (SILVA A, 2020). Esse fator é influenciado pelas oportunidades de trabalho estarem concentradas nos grandes centros, onde estão dispostas as maiores economias e produção de riquezas. Estudo exploratório utilizando as informações do Ministério da Educação a respeito da distribuição espacial das IES que oferecem o curso de enfermagem no território brasileiro ratificou que a maior concentração dessas instituições está na região Sudeste, seguido pela região Nordeste (MATSUMURA ESS, et al., 2018).

No que diz respeito as atividades acadêmicas complementares, especificamente projetos de extensão, houve baixa participação dos egressos pesquisados, sendo necessário um processo de reflexão acerca do tema e investigação de seus motivos. A extensão possibilita a interação entre os conhecimentos trazidos pelo universo acadêmico e os diversos setores da comunidade. Essa estratégia traz benefícios como a vivência da realidade aliada a oportunidade de aplicar as teorias aprendidas. Para a população inserida naquele espaço, o maior ganho está na assistência prestada de maneira pragmática, ou seja, uma relação de troca entre as partes. Assim, é possível ampliar as habilidades dos acadêmicos para que compreendam as dificuldades daquele público e levem promoção em saúde de acordo com a realidade desses indivíduos (SILVA ALB, et al., 2019; MICHELON FF e BASTOS MB, 2019).

Do mesmo modo, os resultados encontrados em programas de monitoria mostraram uma adesão modesta. A prática da monitoria está respaldada na Lei 9.394/96 que trata das diretrizes e base da educação, que estabelece que essa atividade deve ser desenvolvida pelo aluno de acordo com sua afinidade na disciplina e seu rendimento acadêmico (BRASIL, 1996). Dessa forma, é desenvolvida através da interação entre docente e discente durante o processo de ensino-aprendizagem que impulsiona o aluno na prática da docência, além de promover sua autonomia nos estudos e alavancar relações interpessoais, habilidades que podem ascender sua atuação profissional (FREITAS CAO e SANTOS ACM, 2019). Em um estudo de revisão bibliográfica foi demonstrado que alguns fatores podem contribuir para uma baixa adesão dos acadêmicos nessa atividade complementar, como por exemplo, a disponibilidade de horário, o desinteresse para atuação na docência e principalmente o desconhecimento da importância da atividade para o currículo do estudante (GALDINO, et al., 2019). 
A participação dos entrevistados concernente aos projetos de iniciação científica se mostrou semelhante ao das outras atividades mencionadas. Para além de uma formação crítica reflexiva, a vivência no campo da pesquisa constrói profissionais engajados e capacitados para construção de saberes com foco na melhora da qualidade de vida da população, a partir da evolução da ciência e tecnologia. Estudo sobre a produção científica no Brasil, publicado pela Coordenação de Aperfeiçoamento de Pessoal de Nível Superior (CAPES), mostra que mais da metade da ciência produzida no Brasil provém das Universidades públicas, o que evidencia um maior envolvimento em pesquisas destes estudantes em relação aos da rede privada (CAPES, 2019). Um estudo que analisou as contradições da pesquisa e a pós-graduação no país, destacou que a maior barreira enfrentada pelas Instituições privadas é a falta de financiamento público, já que os custos do trabalho não podem ser imputados ao estudante (SOARES PC, 2018).

A atividade com maior abarcamento por parte dos egressos nesta pesquisa foi o estágio extracurricular, inclusive foi a resposta prevalente quando perguntado qual a atividade extracurricular mais importante para a atuação profissional. No Brasil as modalidades de estágios estão regidas pela Lei 11.788/08 que estabelece normas para o cumprimento e execução dessa atividade. A contratação pode variar entre curricular ou extracurricular. No primeiro modo, de forma obrigatória, o estudante deverá cumprir carga horária estabelecida pelas Diretrizes Curriculares do projeto pedagógico do curso para a sua graduação. De forma diferente, no modelo extracurricular a participação é facultada ao acadêmico e está prescrito o pagamento de bolsa auxílio, auxílio transporte e recesso remunerado. As atividades exercidas pelo estagiário devem ser executadas sob a supervisão direta do preceptor (BRASIL, 2008).

O estágio tem como objetivo aprimorar e desenvolver competências comportamentais frente as necessidades das Instituições como o trabalho em equipe, além de conciliar teoria à prática. A oportunidade de realização exaustiva de procedimentos técnicos privativos do enfermeiro também constitui vantagem em vivenciar esta praxe (DA SILVA AC, et al., 2020). Estudo realizado na Universidade Estadual de Faria de Santana na Bahia, com 171 graduandos do curso de medicina, apresentou resultado semelhante ao encontrado neste artigo, evidenciando que o estágio extracurricular constitui umas das atividades priorizadas pelos acadêmicos daquele curso, mesmo tendo perdas com carga não aproveitada para o currículo (CRUZ MLS, et al., 2020).

Quando analisado o ingresso no mercado de trabalho, percebeu-se que a maior parte conquistou o primeiro emprego em até seis meses após a graduação através de testes de entrevistas com predominância nas Instituições Públicas. Um estudo sobre a análise do tempo médio para inserção no mercado de trabalho de recém formados relaciona a conjuntura da economia, exigências do mercado e de políticas vivenciadas no país à época da conclusão do curso. Fatores como condições de trabalho e a demanda de vagas versus a oferta de enfermeiros refletem esse macro cenário (PUSCHEL VAA, et al., 2017). Uma pesquisa qualitativa com gestores e empregadores da enfermagem juntamente com os coordenadores dos cursos de enfermagem do estado do Rio Grande do Norte, evidenciou o cenário desfavorável da empregabilidade naquela Unidade da Federação. Dentre os fatores apontados para essa situação foi a alta oferta de vagas em cursos de enfermagem que impulsiona a competitividade, tornando ainda mais seletiva a contratação desses profissionais (OLIVEIRA JSA, et al., 2018).

Resultados de pesquisa sobre os desafios da saúde e trabalho da enfermagem no Brasil expõe que o setor público através da resistência do Sistema Único de Saúde (SUS) ainda é o maior empregador da enfermagem, apesar da precariedade das condições de trabalho (SILVA MCN e MACHADO MH, 2020). Ao analisar a carga horária, nota-se que a maioria dos enfermeiros trabalham 40 horas semanais ou mais. Resultados semelhantes foram encontrados em outros estudos sobre a temática da carga horária do profissional de enfermagem (BIFF D, et al., 2020 e OLIVEIRA BLCA, et al., 2018). Dentre os profissionais que compõem a equipe de saúde, a enfermagem é a categoria profissional que permanece 24 horas presente na assistência ao paciente. $O$ enfermeiro desenvolve funções no decorrer de sua jornada diária que envolve desde a prestação do cuidado até a gerência da equipe e do setor em que está lotado. Esta carga de trabalho é considerada pesada e pode trazer consequências graves tanto para a saúde do trabalhador quanto para a qualidade da assistência prestada (BIFF D, et al., 2020). 
Uma ampla discussão sobre o tema vem se arrastando entre os agentes das Entidades da Classe da Enfermagem e de outras categorias, juntamente com o Poder Legislativo desde o ano de 2000 através do Projeto de Lei ํo 2295 que propõe a diminuição da carga horária semanal para 30 horas. Porém, nenhum resultado efetivo foi implementado após essas discussões, sob o argumento das implicações nos custos das Instituições, principalmente as de natureza privada. Esse pleito se torna mais urgente devido à crise sanitária no país e no mundo frente aos profissionais no enfrentamento da pandemia, com agravamento do estresse pelas condições da execução do trabalho, além do acometimento da doença nesses trabalhadores (BORGES EMN, et al., 2021).

A média salarial dos respondentes desta pesquisa, foi de até 3 salários mínimos. Em um trabalho realizado com egressos da Universidade de São Paulo foi encontrado resultado semelhante, o que demonstra ser essa a realidade do mercado (PUSCHEL VAA, et al., 2017). Embora outro estudo demonstre que o Sudeste do seja a região que melhor remunera, vale ressaltar que a demanda de profissionais em menor número no Nordeste parece exercer influência na composição da média salarial demonstrado no estudo alvo (BARBOSA ACS, et al., 2019). Em um mapeamento da formação do enfermeiro no Brasil, revelou que há um fenômeno migratório crescente no mercado por melhores condições de vida e de trabalho oferecidos onde a mão de obra é escassa. Os destinos mais procurados são alguns países da Europa como a Suíça, além dos USA e Nova Zelândia (FROTA MA, et al.,2020).

No que diz respeito a continuação da formação, torna-se importante, pois, investir numa especialização amplia as chances de conseguir um posto de trabalho, além de contribuir para a melhora o ordenado mensal (PUSCHEL VAA, et al., 2017). Neste estudo verificou-se predominância para pós-graduações do tipo Latu Senso. Esse tipo de especialização objetiva assimilar ainda mais o conhecimento sobre uma área específica do saber. No Brasil, esse título é regulamentado e reconhecido pelo Ministério da Educação através da Resolução CNE/CES 1/2007 (BRASIL, 2007). As especialidades mais procuradas pela população que fez parte deste estudo foram as em UTI e Urgência e Emergência, confirmando a assistência hospitalar como 0 setor que mais absorve a mão de obra do enfermeiro (MACHADO MH, et al., 2020).

\section{CONCLUSÃO}

A pesquisa conseguiu demonstrar o perfil socioeconômico, demográfico, acadêmico e profissional dos egressos de uma IES do estado de Pernambuco, além de evidenciar que as atividades acadêmicas complementares contribuíram para a atuação profissional dos enfermeiros no mercado de trabalho. Concluise que incentivar a adesão dos discentes nesses programas pode promover a uma melhor preparação para o mercado de trabalho, além de proporcionar segurança na execução das atividades laborais do enfermeiro. No entanto, ficou demonstrado que o estágio extracurricular contribui como ferramenta para galgar uma alocação profissional como também uma estratégia para gerar relacionamentos interpessoais e profissionais com foco no crescimento e desenvolvimento da profissão.

\section{REFERÊNCIAS}

1. BARBOSA ACS, et al. Perfil de egressos de Enfermagem: competências e inserção profissional. Revista Latino-Am. Enfermagem, 2019; 27: 1-9.

2. BASTOS MF, SCARABELI ZN. Gênero e a profissão de enfermagem: Mulheres, simbologias, condutas e vestimentas em meados do século XX. Caminhos da História, 2020; 22: 31-44.

3. BECERRIL LC. O humanismo na formação e prática na enfermagem: uma esperança transformadora. Texto completo - enferm., 2016; 25(1): editorial.

4. BIFF D, et al. Cargas de trabalho de enfermeiros: Luzes e sombras na Estratégia em Saúde da Família. Ciênc. saúde coletiva, 2020; 25: 147-158.

5. BORGES EMN, et al. Percepções e vivências de enfermeiros sobre o seu desempenho na pandemia da COVID19. Rev. Rene, 2021; 22: e60790.

6. BRASIL. Conselho Nacional de Educação (CNE). 2001. Disponível em: http://portal.mec.gov.br/escola-de-gestoresda-educacao-basica/323-secretarias-112877938/orgaos-vinculados-82187207/12991-diretrizes-curriculares-cursosde-graduacao. Acessado em 20 de abril de 2021. 
7. BRASIL. Instituto Brasileiro de Geografia e Estatística (IBGE). Estudos e Pesquisas. Informação Demográfica e Socioeconômica. 2019. Disponível em: https://www.ibge.gov.br/estatisticas/sociais/populacao/25844-desigualdadessociais-porcor-u\%20raca.html?=\&t=publicacoes. Acessado em: 20 de abril de 2021.

8. BRASIL. Instituto Nacional de Estudos e Pesquisas Educacionais Anísio Teixeira (INEP). Censo da Educação Superior. 2019. notas estatísticas. Disponível em: https://www.gov.br/inep/pt-br/areas-de-atuacao/pesquisasestatisticas-e-indicadores/censo-da-educacao-superior. Acessado em: 20 de abril de 2021.

9. BRASIL. Presidência da República. Casa Civil. 1996. Disponível em: http://www.planalto.gov.br/ccivil_03/leis/19394.htm. Acessado em 19 de abril de 2021.

10. CONSELHO FEDERAL DE ENFERMAGEM (COFEN). Pesquisa inédita traça o perfil da enfermagem. 2015. Disponível em: https://portal.coren-sp.gov.br/noticias/pesquisa-inedita-traca-perfil-da-enfermagem-no-brasil-e-emsao-paulo/. Acessado em: 08 de abril de 2021.

11. COORDENAÇÃO DE APERFEIÇOAMENTO DE PESSOAL DE NÍVEL SUPERIOR (CAPES). Coordenação de Aperfeiçoamento de Pessoal de nível superior. A pesquisa no Brasil: Promovendo a excelência. 2019. Disponível em: http://mailer.periodicos.capes.gov.br/?m=119\&p=view\&pi=ViewBrowserPlugin\&uid=11e8f60055a1b7ef8d066f61704ff 3c9. Acessado em: 11 de abril de 2021.

12. CRUZ MLS, et al. Perfil das Atividades Complementares dos Graduandos em Medicina pela Universidade Estadual de Feira de Santana, 2009-2017. Revista Brasileira de Educação Médica, 2020; 43: 265-275.

13. DA SILVA A, et al. Um breve histórico das atividades extracurriculares na formação do enfermeiro enquanto prática acadêmica. Revista Internacional de apoyo a la inclusión, logopedia, sociedad y multiculturalidad, 2018; 3: 4.

14. FREITAS CAO, SANTOS ACM. Uso de metodologias ativas no ensino de práticas de Enfermagem. Res. Enferm UFPE online, 2019; 13: 1-6.

15. FROTA MA, et al. Mapeando a formação do enfermeiro no Brasil: desafios para atuação em cenários complexos e globalizados. Ciênc. saúde coletiva, 2020; 25: 25-35.

16. GALDINO ETS, et al. Desafios da monitoria acadêmica: Percepção dos alunos monitores e monitorados. Encontro de Extensão, Docência e Iniciação Científica - EEDIC, 2019; 5: 1.

17. LEAL LA, et al. Clinical and management skills for hospital nurses: perspective of nursing university students. Revista Brasileira de Enfermagem, 2018; 71: 1514-1521.

18. MACHADO MH, et al. Características gerais da enfermagem: o perfil sociodemográfico. Enfermagem em Foco, 2016; 7: 686 .

19. MACHADO MH, et al. Mercado de trabalho e processos regulatórios - a Enfermagem no Brasil. Ciênc. saúde coletiva, 2020; 25: 25-35.

20. MASSAROLI A, et al. Competências para enfermeiros generalistas e especialistas atuarem na prevenção e controle de infecções no Brasil. Rev. Latino-Am. Enfermagem, 2019; 27: e3134.

21. MATSUMURA ESS, et al. Distribuição espacial dos cursos de graduação em enfermagem. Rev. Enferm. UFPE online, 2018; 12: 3271-3278.

22. MICHELON FF, et al. Ações extensionistas e o diálogo com as comunidades Contemporâneas. Coleção Extensão e Sociedade 2. Ed. da UFPel, 2019; 160 p.

23. NETTO L, et al. Prática reflexiva e formação profissional: aproximações teóricas no campo da saúde e da Enfermagem. Escola Anna Nery, 2018; 22(1): e20170309.

24. OLIVEIRA JSA, et al. Tendências do mercado de trabalho de enfermeiros/as na visão de gestores. Revista Brasileira de Enfermagem, 2018, 71: 148-155.

25. PUSCHEL VAA, et al. O enfermeiro no mercado de trabalho: inserção, competências e habilidades. Revista Brasileira de Enfermagem, 2017; 70: 1-8.

26. RODRIGUES CDS. A formação e inserção profissional do enfermeiro no Brasil: questão em debate na atualidade. Enfermagem Brasil, 2020, 10: 3-4.

27. SILVA A. Análises das implicações psicossociais dos processos de migração rural-urbano de jovens universitários. Tese (Doutorado) - Programa de Pós Graduação em Psicologia. Universidade Federal do Ceará, Fortaleza, 2020; $239 f$.

28. SILVA ALB, et al. Importância da extensão universitária na formação profissional: projeto canudos. Rev. Enferm UFPE online, 2019; 13: e242189.

29. SILVA KL, et al. Enfermeiros migrantes no Brasil: características demográficas, fluxos migratórios e relação com o processo de formação. Rev. Latino-Am. Enfermagem, 2016; 24: e2686.

30. SILVA MCN, MACHADO MH. Sistema de Saúde e Trabalho: desafios para a Enfermagem no Brasil. Ciência saúde coletiva, 2020; 25: 7-13.

31. SOARES, PC. Contradições na pesquisa e pós-graduação no Brasil. Estud. Av, 2018; 32: 289-313.

32. SOUZA JDFS. O ensino crítico reflexivo para a tomada de decisão na formação do enfermeiro: uma questão de competências. Dissertação (Mestrado Acadêmico em Ciências do Cuidado em Saúde) -Universidade Federal Fluminense, Niterói, 2017; 112 p.

33. SOUZA NVDO, et al. Formação em enfermagem e mundo do trabalho: percepções de egressos de enfermagem. Aquichan, 2017; 17: 204-216. 